\title{
Laboratory Testing on Energy Absorption of High-Damping Rubber in a New Bolt for Preventing Rockburst in Deep Hard Rock Mass
}

\author{
Lu Chen $(\mathbb{D}$, Qingwen Li $\mathbb{D}$, Jianming Yang, and Lan Qiao \\ Department of Civil Engineering, University of Science and Technology Beijing, Beijing 100083, China \\ Correspondence should be addressed to Qingwen Li; qingwenli@ustb.edu.cn
}

Received 15 August 2017; Revised 22 March 2018; Accepted 24 April 2018; Published 27 June 2018

Academic Editor: Longjun Dong

Copyright (C) $2018 \mathrm{Lu}$ Chen et al. This is an open access article distributed under the Creative Commons Attribution License, which permits unrestricted use, distribution, and reproduction in any medium, provided the original work is properly cited.

\begin{abstract}
With the increase in mining depth, the deep hard rock mass is under threat of rockburst under high geostress, high temperature, high osmotic pressure, and strong disturbance. To reduce the probability and strength of rockburst, a new energy-absorbing bolt for guaranteeing the stability of deep hard rock mass was developed utilizing the energy absorption characteristic of high-damping rubber. To analyze the practicability and obtain the quantified behaviors of this new energy-absorbing bolt, a series of impact tests on specimens of high-damping rubber, granite, and granite-rubber composite specimens was carried out by a split Hopkinson pressure bar (SHPB) method. Further, considering the different working depths with different rock temperatures, the dynamic energy-absorbing characteristics of high-damping rubber under different temperatures were tested. The testing results show that the new energy-absorbing bolt can consume the storage energy in host rock effectively, and the environmental temperature will produce certain effects on the energy-consuming rate. In addition, the optimal energy-absorbing thickness-diameter ratio of highdamping rubber was confirmed by SHPB tests.
\end{abstract}

\section{Introduction}

As shallow resources decrease constantly, people must pursue much deeper resources. Therefore, the excavation depths of mines are becoming deeper, and kilometer-level and even deeper mining are becoming normal. In a deep underground environment, the high geostress, high temperature, high pore pressure, and strong disturbance will result in stronger rockburst and other dynamic disasters, which seriously threaten mine safety. Rockburst is a serious disaster affecting an excavation or pillars. It occurs in a sudden or violent manner and is associated with a seismic event, especially during deep mining. It can cause serious casualties, mechanical damage, project delays, and economic loss. Increasingly, scholars are paying attention to its occurrence mechanism $[1,2]$, influencing factor [3], and monitoring method [4, 5]. In a constantdepth study, researchers found that it is easier to understand the nature of rockbursts by adopting energy theory. Jiang et al. (2010) studied rockburst characteristics based on the new energy index in a 2500-m depth tunnel [6]; Kornowski and
Kurzeja (2012) predicted rockburst probability by employing the given seismic energy [7]. Sirait et al. (2013) also predicted the rockburst by using the principle of energy balance [8]. Weng et al. (2017) adopted the strain energy density index to analyze the rockburst characteristics of roadways in the Linglong gold mine, China [9]. For increasingly serious rockburst disasters, people have tried some active defense methods to release the storage energy in the host rock, such as the deep-hole directional fracturing method [10], blasting fracturing method [11], hydraulic fracturing method [12], and optimization of mining parameters [13,14].

Despite much effort, these active defense methods cannot work well, so the best processing method is still using the rock bolts to resist the impact, instability, and rockfall [15-20]. Also taking advantage of the principle of energy, the concept of an energy-absorbing bolt was proposed in South Africa in the early 1990s [21]. Subsequently, many kinds of energyabsorbing bolt were developed; Ansell (2005) developed a new type of energy-absorbing rock bolt that can absorb the kinetic energy by utilizing the plastic lengthening of steel bars 


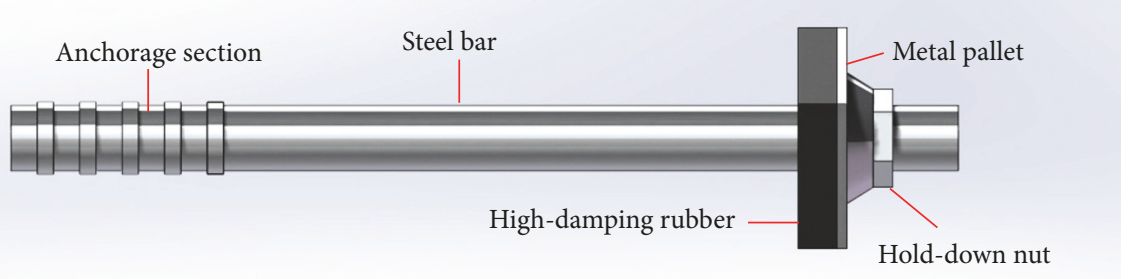

FIGURE 1: Schematic diagram of energy-absorbing bolt.

[22], and the dynamic testing was carried out in his next study [23]; Li (2010) proposed a new energy-absorbing bolt for rock support in high-stress rock masses, a D-bolt with deformable sections [24]; then, the performance of D-bolts under static loading [25] and dynamic loading [26] was studied in 2012. Wang et al. (2013) did quasistatic laboratory testing of a novel rock bolt for energy-absorbing applications. The results show that the bolt can accommodate large deformations without experiencing serious damage [27]. He et al. (2014) developed a novel energy-absorbing bolt with extraordinarily large elongation and constant resistance, called a cone bolt [28]. Liang et al. (2017) further proposed a mechanical model for cone bolts by analyzing the cone anchorage function as a wedge-style mechanical anchor [29].

The above-mentioned energy-absorbing bolts all permit a larger deformation between the bolt and rock mass to realize stress unloading and energy absorbing. However, for the deep hard rock, such as granite in a deep gold mine or a deep iron ore mine, the rockburst type mainly is strain rockburst. This means that there will be a very small deformation of the rock mass when the rockburst occurs. Thus, current energy-absorbing bolts may not guarantee the stability of deep hard rock mass well. Moreover, rockburst is a dynamic problem, and some of the mentioned research was based on static tests, which are not suitable for the dynamic problem. With the purpose of reducing the probability and strength of rockbursts and using as an example the high-damping rubber employed in structural seismic engineering [30-36], a new energy-absorbing bolt with highdamping rubber must be developed to guarantee the stability of deep hard rock mass. High-damping rubber is the key assembly unit for dynamic energy absorption in this bolt. Hence, the energy-absorbing behaviors of high-damping rubber should be analyzed systematically. Considering the rockburst as a typical dynamic problem, a series of impact tests on specimens of high-damping rubber under different strain rate can be done. Granite-granite and granite-rubber composite specimens can also be carried out by an SHPB system to examine the energy-absorbing effect. For the highdamping rubber material, the energy will be consumed by the resistance between the macromolecular chains, and then the consumed energy can transform into heat exchanging into the surrounding environment. In deep mining, the higher rock temperature is a factor that cannot be ignored, and the environmental temperature may produce certain effects on the energy consumption rate. Thus, the energy-absorbing characteristic of high-damping rubber with different environmental temperatures also should be quantified. Finally, the optimal energy-absorbing thickness-diameter ratio of high-damping rubber was confirmed by SHPB tests.

\section{The Energy-Absorbing Bolt and Its Working Mechanism}

2.1. Structure of Energy-Absorbing Bolt. Because of the high geostress and high temperature environment, the rock mass deep underground will store a mass of strain energy, especially for the unbroken hard rock. After the tunnel or underground structure has been excavated, the stored energy in nearfield host rock will accumulate. If the accumulated energy is larger than the limited energy storage, the superfluous energy must be released at free surfaces or transfer into the inner host rock. Meanwhile, this energy release process will cause plastic damage and even detritus to be thrown. Because of the particular characteristics of hard rock, usually very small deformation will cause the rock to fracture, and the larger stored energy will produce a stronger rockburst. According to this and taking advantage of the principle of energy conservation, if part of the accumulated energy could be consumed smoothly, the rockbursts would be controlled effectively. A new energy-absorbing bolt that uses highdamping rubber, called an R-bolt, is presented in Figure 1.

As shown in Figure 1, the R-bolt is composed of an anchorage section, steel bar, high-damping rubber, metal disc, and hold-down nut. The steel bar is processed by round steel with a rough anchorage segment at the bottom and a screwed end at the top. The high-damping rubber blanket is placed adjoining the rock mass. The damping ratio of current high-damping rubber materials in the market is from $10 \%$ to $24 \%$, and rubber with a $15 \%$ damping ratio was selected in this study. When the R-bolt is under an impact, the shock energy from the rock mass could be consumed by the viscous resistance, to reduce the risk of the rockburst effectively.

\subsection{Energy-Absorbing Mechanism of Higher Damping Rubber.} Under dynamic load, the high-damping rubber will suffer cyclic deformation. In addition, the high-damping rubber is a viscous-elastic material, and its strain change always lags behind the stress change. The typical response of sinusoidal stress and strain can be expressed by the following formula:

$$
\begin{aligned}
& \sigma(t)=\sigma_{0} \sin (\omega t+\xi), \\
& \varepsilon(t)=\varepsilon_{0} \sin \omega t,
\end{aligned}
$$

where $\sigma_{0}$ is the stress amplitude, $\varepsilon_{0}$ is the strain amplitude, $\omega$ is the angular frequency of periodic change, $t$ is the time, and $\xi$ is the phase difference between stress and strain. 
TABLE 1: Physical and mechanical parameters of high-damping rubber (provided by supplier).

\begin{tabular}{lccccccc}
\hline Damping ratio & Stiffness & Tensile strength & Elongation at failure & Tear strength & Shear modulus & Density & Compression set value \\
\hline 15 & 75 & $17.22 \mathrm{MPa}$ & 436 & $80 \mathrm{~N} / \mathrm{mm}$ & $1.33 \mathrm{MPa}$ & $1.22 \mathrm{~g} / \mathrm{cm}^{3}$ & $<25 \%$ \\
\hline
\end{tabular}

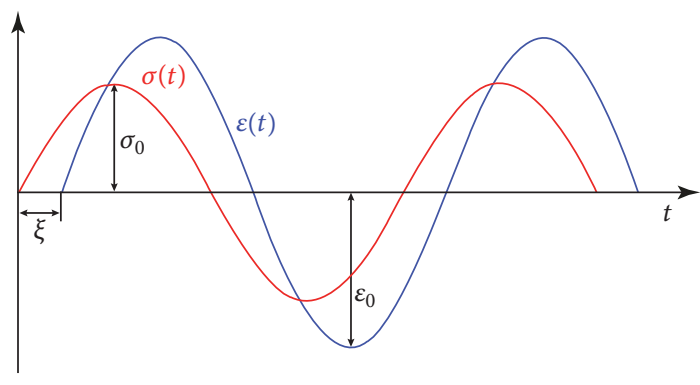

FIGURE 2: Response of sinusoidal stress and strain in high-damping rubber.

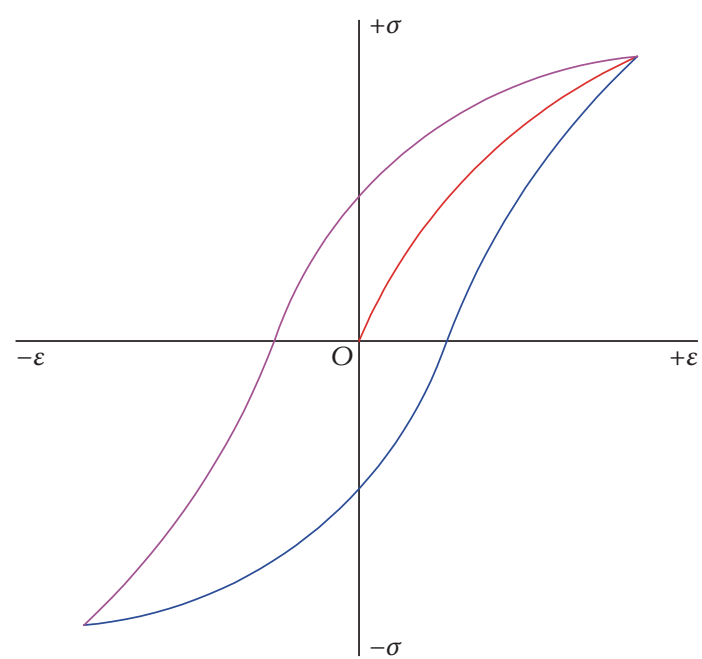

FIGURE 3: The dynamic sketch curve between stress and strain.

Following the above formulas, the schematic diagram of sinusoidal stress and strain in high-damping rubber is shown in Figure 2.

As shown in Figure 2, the strain lags behind the stress; hence, the relationship between the stress and strain is not linear, and there is a stable hysteresis loop, as shown in Figure 3.

In Figure 3, the area of the hysteresis loop is the value of absorbing energy in a vibrational period (damping rate), and it can be calculated by the curvilinear integral,

$$
\Delta W=\int_{0}^{2 \pi / \omega} \sigma d \varepsilon=\int_{0}^{2 \pi / \omega} \sigma \frac{d \varepsilon}{d t} d t .
$$

According to the definition of modulus, the synchronous change ratio between stress and strain is the storage modulus $E^{\prime}$, which is reflected in the stretching-crimping movement of macromolecular chains during the reciprocating deformation. The ratio between stress and strain with phase difference $\delta$ is loss modulus $E^{\prime \prime}$, which expresses that the material should overcome the resistance of macromolecular chains. The formulas of storage modulus and loss modulus are

$$
\begin{aligned}
E^{\prime} & =\frac{\sigma_{0}}{\varepsilon_{0}} \cos \delta, \\
E^{\prime \prime} & =\frac{\sigma_{0}}{\varepsilon_{0}} \sin \delta, \\
E & =E^{\prime}+E^{\prime \prime},
\end{aligned}
$$

where $\sigma_{0}$ is the stress, $\varepsilon_{0}$ is the strain, and $E$ is the total modulus.

Thus, the absorbing energy $\Delta W$ could be further deduced as

$$
\begin{aligned}
\Delta W & =\int_{0}^{2 \pi / \omega} \omega \varepsilon_{0}^{2}\left(E^{\prime} \sin \omega t \cos \omega t+E^{\prime \prime} \cos ^{2} \omega t\right) d t \\
& =4 \varepsilon_{0}^{2}\left(\frac{E^{\prime}}{2}+\pi \frac{E^{\prime \prime}}{4}\right) .
\end{aligned}
$$

As introduced above, the high-damping rubber with a $15 \%$ damping rate was selected to perform the laboratory tests. The physical and mechanical parameters are listed in Table 1.

2.3. Energy-Absorbing Mechanism of R-Bolt. When the host rock is excavated, the large quantity of elastic energy will be adjusted and increased in surrounding rock. The higher stored elastic energy maybe induces the rockburst. During the rockburst process, part of the stored energy will be consumed by rock fracture and crack friction, and the residual energy is the kinetic energy of rock blocks. If there is an additional device to consume some more stored energy, the tendency and intensity of rockburst will be reduced. As shown in Figure 1, the R-bolt is composed of an anchorage section, steel bar, high-damping rubber, metal disc, and holddown nut. After the R-bolt is set in the rock mass, the highdamping rubber blanket is placed between the rock mass and the metal disc, and some of the stored elastic energy in rock mass will be transmitted to deformation energy of highdamping rubber and then transferred to thermal energy due to macromolecular chains' effect. The working principle of Rbolt was shown in Figure 4.

For the placing density of the R-bolt, the typical pressure arch theory of bolt is adopted to confirm the number of Rbolts [38].

\section{SHPB System and Absorbed Energy Analysis}

3.1. SHPB System. To understand the dynamic energyabsorbing characteristics, the SHPB system in North China University of Science and Technology (Hebei Province, 


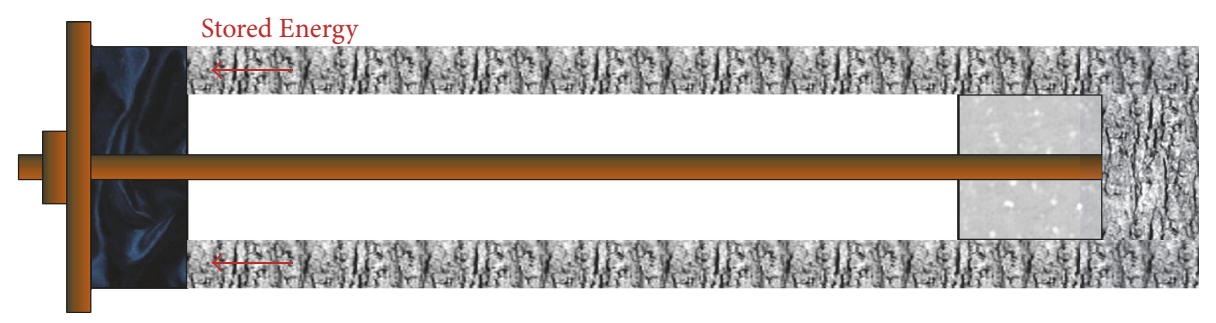

(a)

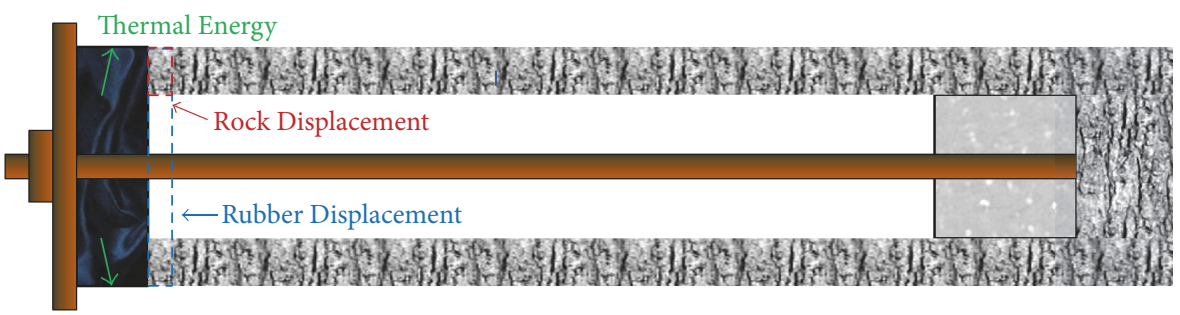

(b)

FIGURE 4: Working principle of energy absorption bolt.

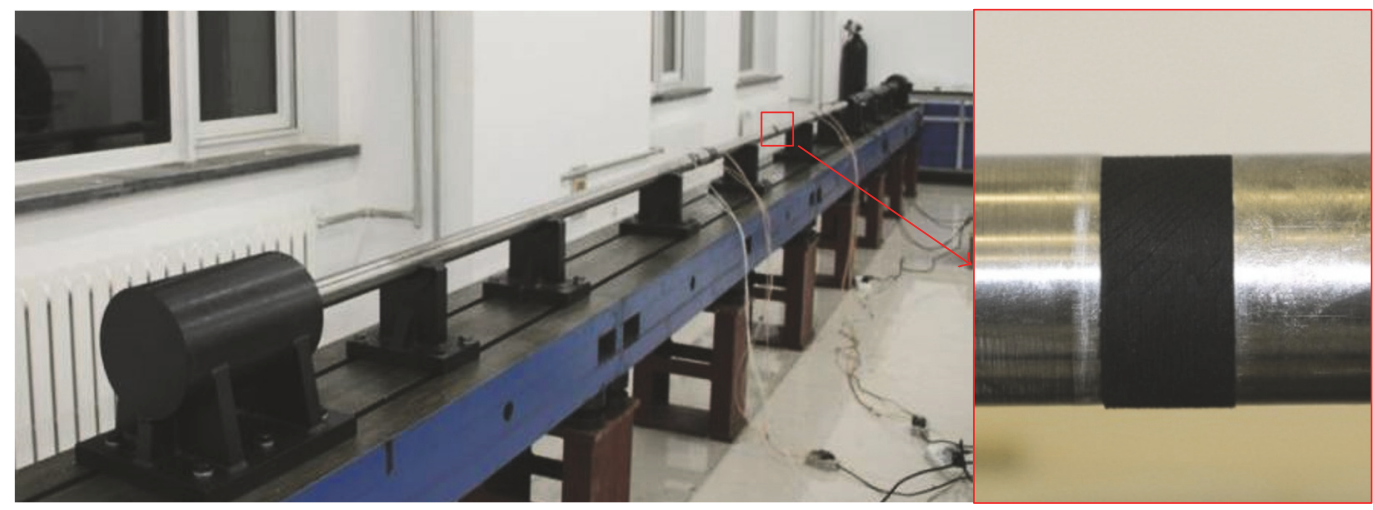

FIgURE 5: The diagram and physical photo of the SHPB test system.

China) was used. The typical SHPB test system comprises three systems: the power system, the work system, and the monitoring system. The power system contains a pressure chamber. The work system contains the impact bar, incidence bar, and transmission bar. The monitoring system contains the laser velocity measurement, the signal-acquiring device, and the high-speed camera. The physical photo of the SHPB test system and tests are shown in Figure 5.

3.2. Energy Analysis Using SHPB System. Without considering the friction effect between the test bars and specimen and by adopting the principle of energy conservation, the absorbed energy of the specimen could be confirmed by

$$
W_{c}(t)=W_{i}(t)-W_{r}(t)-W_{t}(t),
$$

where $W_{c}(t)$ is the absorbed energy, $W_{i}(t)$ is the incident energy, $W_{r}(t)$ is reflected energy, and $W_{t}(t)$ is the transmitted energy. Each type of energy can be calculated by

$$
\begin{aligned}
W_{x}(t) & =\int_{0}^{t} A_{x} \sigma_{x}(t) C_{0} \varepsilon_{x}(t) d t, \\
\sigma_{x}(t) & =E_{0} \varepsilon_{x}(t),
\end{aligned}
$$

where $A_{x}$ is the cross-sectional area of the bar. In this test, the cross-sectional area of the bar is the uniform section, so $A_{x}=A_{0}$, and $C_{0}$ is the stress wave propagated in the test bars, $E_{0}$ is the elastic modulus of the test bars, $\sigma_{x}(t)$ are the stress time histories of the incident wave, reflected wave, and transmitted wave, and $\varepsilon_{x}(t)$ are the corresponding strain time histories. Hence, the incident energy $W_{i}(t)$, reflected energy $W_{r}(t)$, and transmitted energy $W_{t}(t)$ could be expressed as

$$
\begin{aligned}
& W_{i}(t)=E_{0} C_{0} A_{0} \int_{0}^{t} \varepsilon_{i}^{2}(t) d t, \\
& W_{r}(t)=E_{0} C_{0} A_{0} \int_{0}^{t} \varepsilon_{r}^{2}(t) d t, \\
& W_{t}(t)=E_{0} C_{0} A_{0} \int_{0}^{t} \varepsilon_{t}^{2}(t) d t,
\end{aligned}
$$




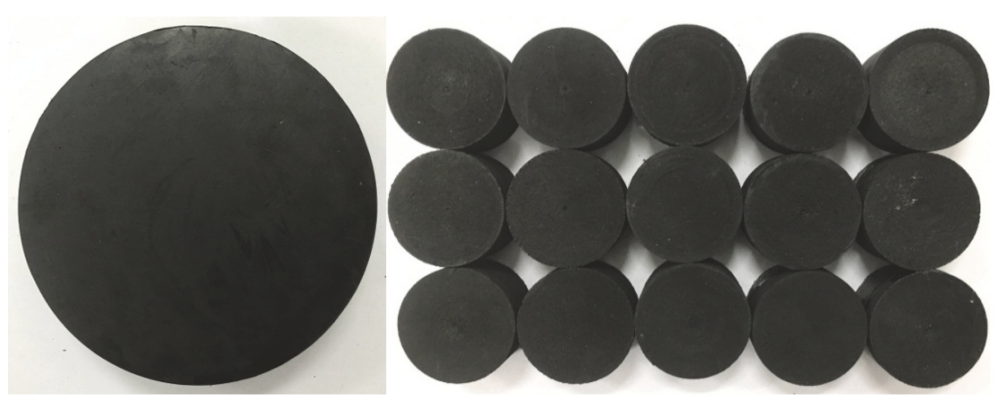

FIGURE 6: The preparative samples of high-damping rubber.

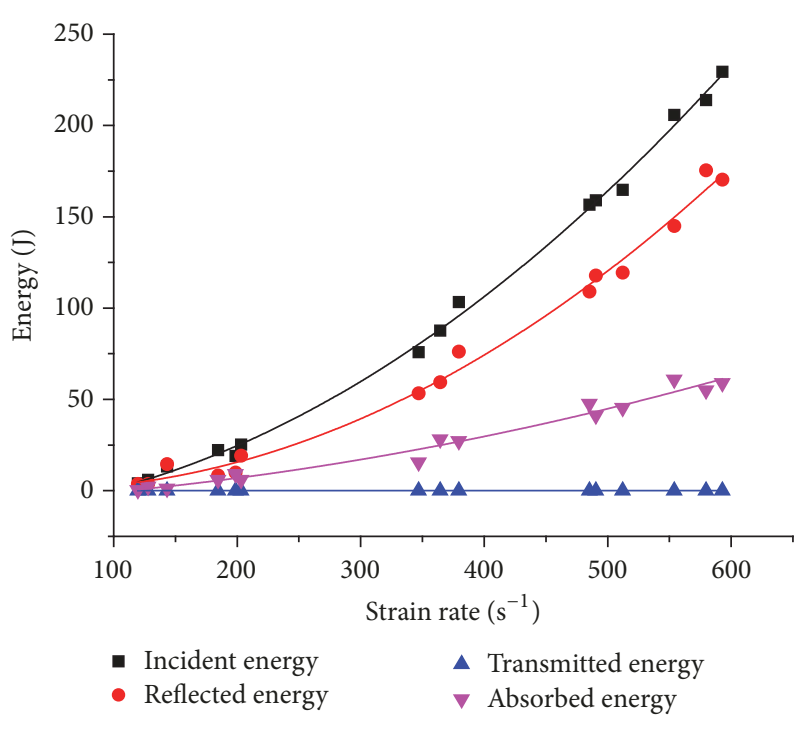

FIGURE 7: Each type of energy with different strain rates.

where $\varepsilon_{i}(t), \varepsilon_{r}(t)$, and $\varepsilon_{t}(t)$ could be monitored by the superdynamic collection instrument.

\section{SHPB Test Results and Energy-Absorbing Analysis}

4.1. Energy-Absorbing Characteristic of High-Damping Rubber. To understand the energy-absorbing characteristics of highdamping rubber, 15 rubber samples with $50-\mathrm{mm}$ diameter and $25-\mathrm{mm}$ height were cut from a rubber plate, and the rubber plate and preparative samples are shown in Figure 6.

After SHPB tests were carried out under different strain rates, each kind of energy could be calculated by formula (5), and the curves of each type of energy with different strain rates are shown in Figure 7.

As the fitted results in Figure 7, with the strain rate increase, the incident energy and reflected energy are the quadratic-form increase, but the transmitted energy is stable at $0.16 \sim 0.2 \mathrm{~J}$. The difference indicated that the high-damping rubber can absorb part of the input energy, except that a certain energy was reflected at the interface of the incident bar and rubber samples. The relationship between the absorbed energy and incident energy and the energy-absorbing rate are shown in Figures 8(a) and 8(b).

In Figure 8, it is shown that the absorbed energy is linear to the total incident energy, which means the high-damping rubber can consume more energy under a stronger impact. For a $100 \mathrm{~s}^{-1}$ to $600 \mathrm{~s}^{-1}$ impact load, the energy-absorbing rates are mainly between $25 \%$ and $30 \%$.

4.2. Energy-Absorbing Characteristic under Different Environmental Temperatures. For the high-damping rubber material, the energy is consumed by the resistance between the macromolecular chains, and then the consumed energy can transform as the heat exchanging to the surrounding environment. Thus, the surrounding environmental temperature may have an effect on the energy-absorbing rate. Furthermore, considering the higher rock temperature in a deep underground environment, five groups of 25 rubber SHPB tests with different environmental temperatures-indoor temperature $\left(22^{\circ} \mathrm{C}\right), 30^{\circ} \mathrm{C}, 40^{\circ} \mathrm{C}, 50^{\circ} \mathrm{C}$, and $60^{\circ} \mathrm{C}$-and different strain rates were carried out, and the temperature control device and the heated sample are shown in Figure 9.

After the SHPB tests were carried out under different environmental temperatures, the incident energy and absorbed energy were calculated by formula (5). The relationship between the absorbed energy and incident energy under different environmental temperatures is shown in Figure 10(a).

After calculation, the energy-absorbing rates under different environmental temperatures (indoor temperature, $30^{\circ} \mathrm{C}, 40^{\circ} \mathrm{C}, 50^{\circ} \mathrm{C}$, and $60^{\circ} \mathrm{C}$ ) are $29.6 \%, 28.4 \%, 27.5 \%, 23.9 \%$, and $21.4 \%$, respectively, and the variation trend is also shown in Figure 10(b). The testing results show that the energyabsorbing rates are decreasing with the environmental temperatures increasing. There is an obvious inflection point at $40^{\circ} \mathrm{C}$. This means that the environmental temperatures will produce some negative effect on the energy's absorption rate, especially for more than a $40^{\circ} \mathrm{C}$ temperature.

4.3. Energy Distribution and Fractal Features of Composite Specimens. To make a quantitative description of the energy-absorbing characteristic of high-damping rubber, the granite-granite composite specimens and granite-rubber composite specimens were tested by the SHPB system and contrasted. To simulate the real installation condition of the R-bolt, all the composite specimens were compressed 


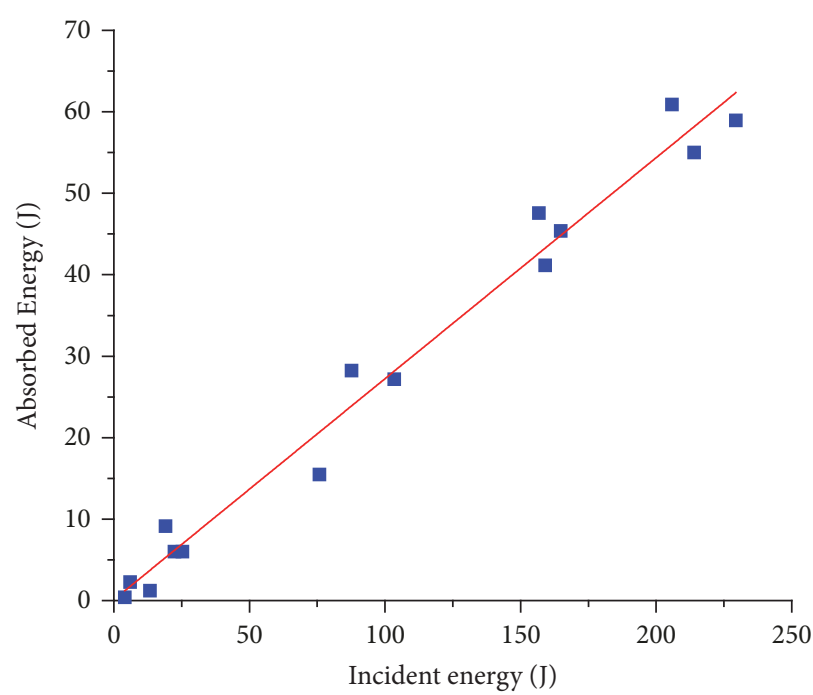

(a)

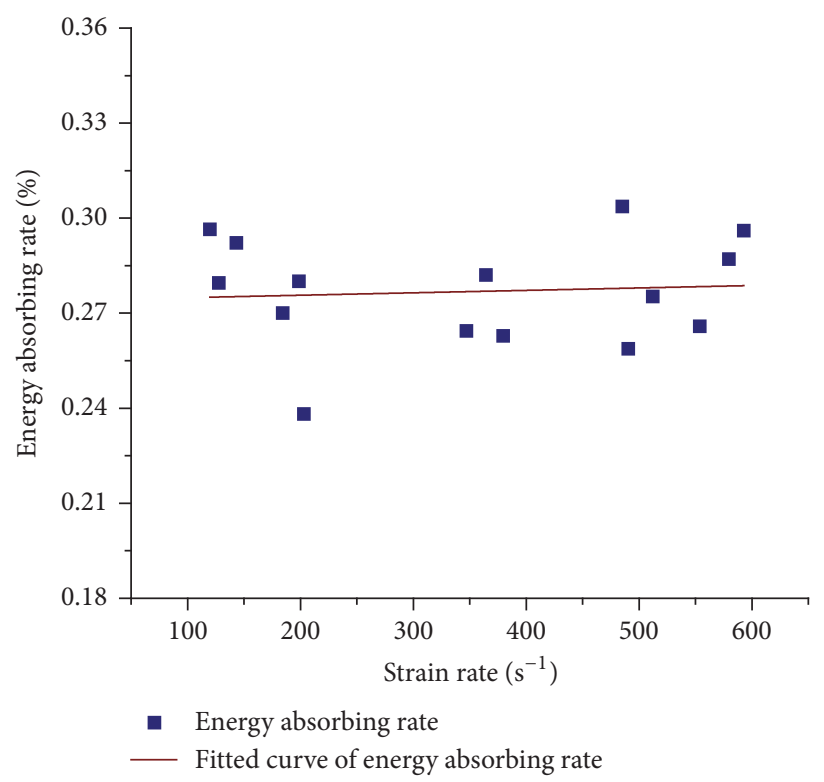

(b)

FIGURE 8: Relationship between the absorbed energy and incident energy and the energy-absorbing rate.

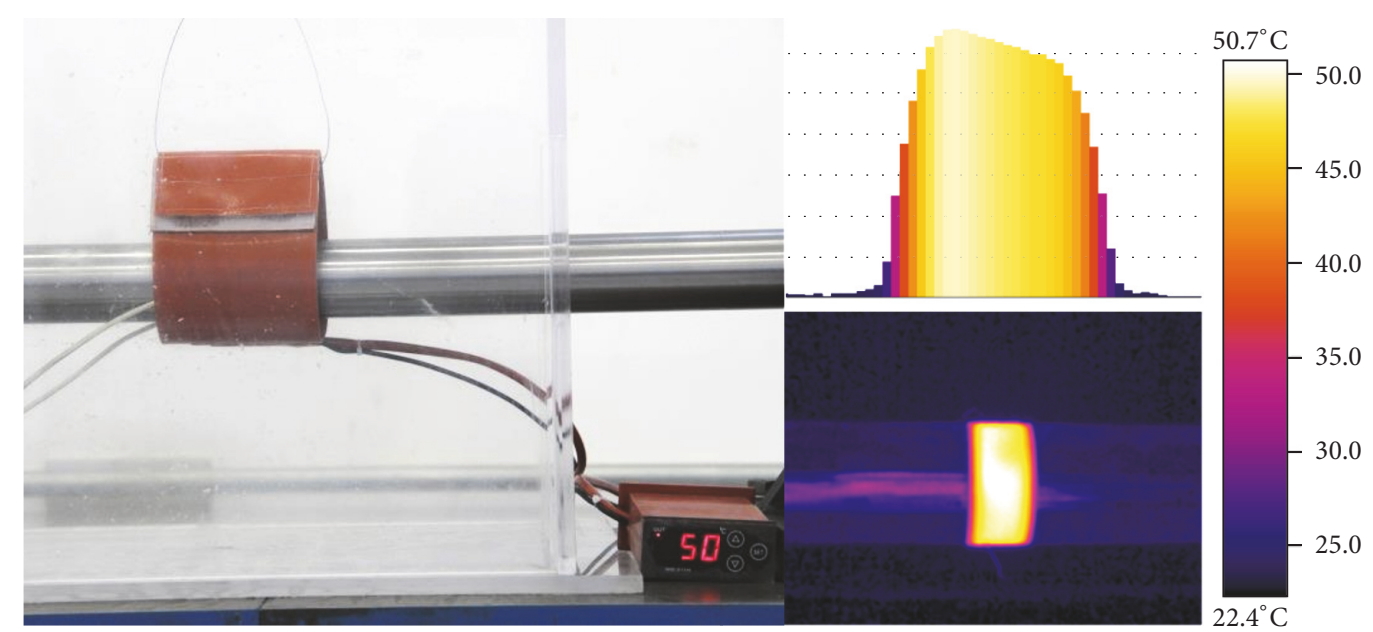

Figure 9: The temperature control device and the heated sample $\left(50^{\circ} \mathrm{C}\right)$.

together without any adhesive. To eliminate the anisotropic effect of rock samples, all the granite samples were drilled from a granite block without any obvious cracks and defects. The composite specimens in the tests are shown in Figure 11.

After six groups of composite specimens were obtained by SHPB, the incident energy, reflected energy, transmitted energy, and absorbed energy of different composite specimens under approximately $200 \mathrm{~s}^{-1}, 300 \mathrm{~s}^{-1}$, and $400 \mathrm{~s}^{-1}$ were obtained, as in Figure 12.

As shown in Figure 12, the average energy-absorbing rate of granite-granite composite specimens is approximately $23 \%$, and the average energy-absorbing rate of granite-rubber composite specimens is approximately $30 \%$. The difference indicates that the rubber plays an important role in consumption of incident energy.
To learn more about the energy absorption effect, the damage degree of granite-granite composite specimens and granite-rubber composite specimens should be analyzed. In this research, the fractal dimension of mass of the fragment size distribution was adopted to describe quantitatively the energy-absorbing characteristic of high-damping rubber. The calculating formulas are

$$
\begin{aligned}
& \alpha=\frac{\lg \left(M_{r} / M_{t}\right)}{\lg r}, \\
& D=3-\alpha,
\end{aligned}
$$

where $M_{r}$ is the mass of rock fragments whose diameter is less than $r, M_{t}$ is the total mass of rock samples, $\alpha$ is the slope of double logarithmic, and $D$ is the fractal dimension of the fragments. 


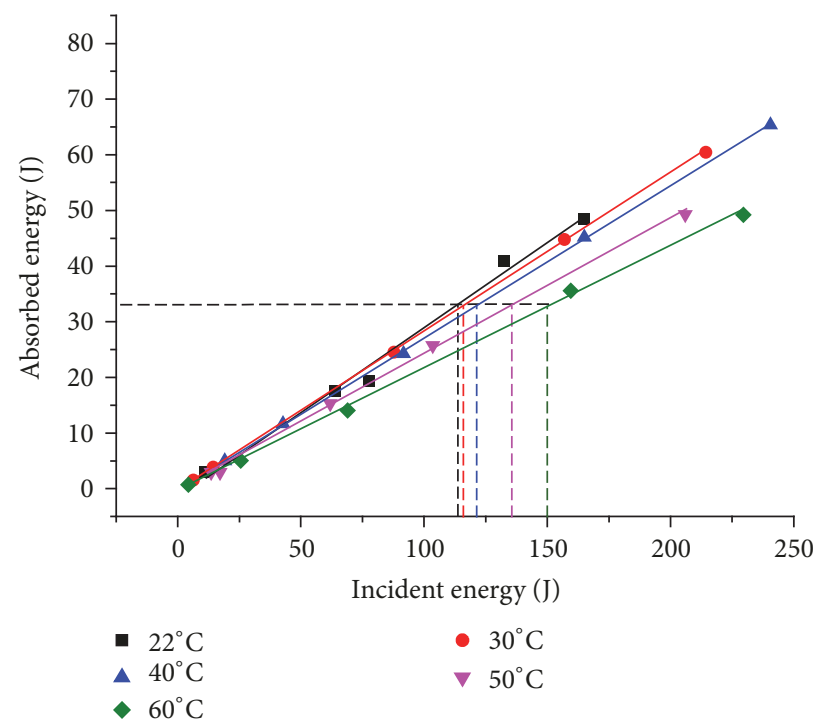

(a)

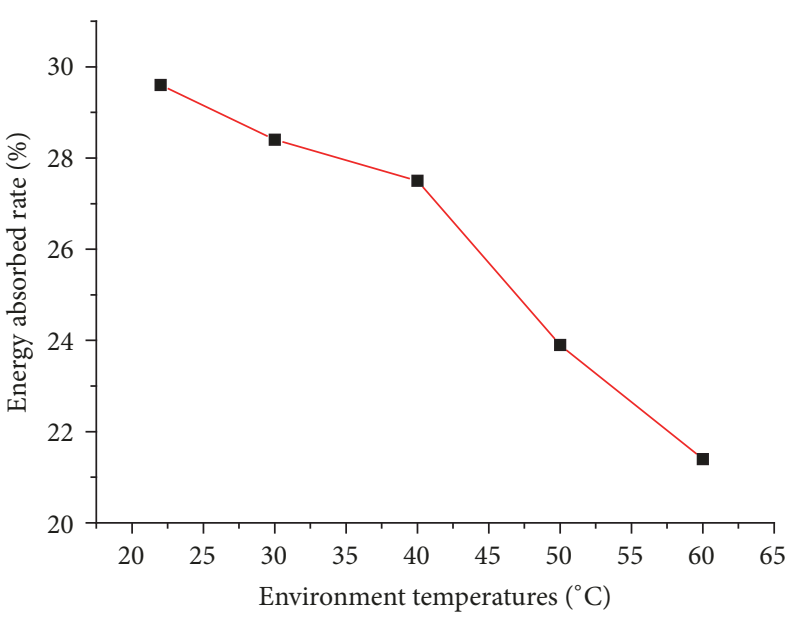

(b)

FIGURE 10: Energy-absorbing rates and their variation trend under different environmental temperatures.

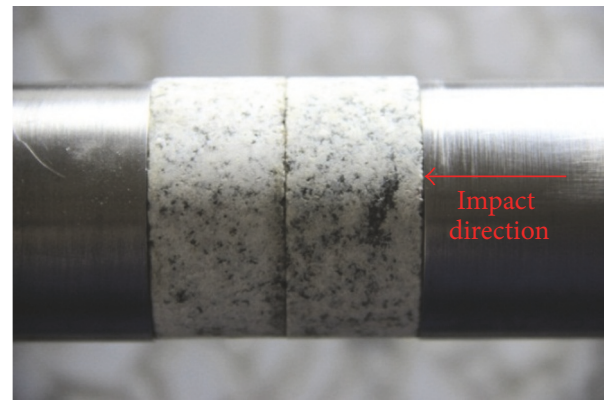

(a) Granite-granite

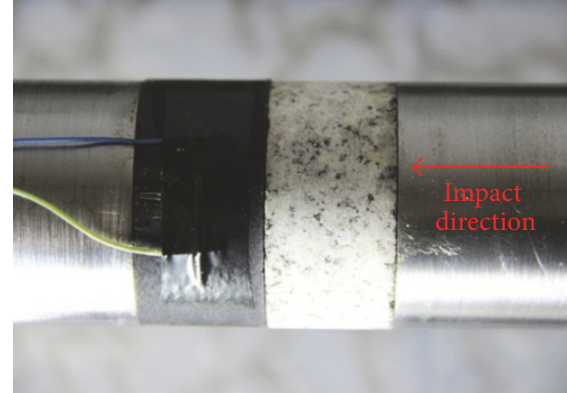

(b) Granite-rubber

FIGURE 11: Composite specimens in SHPB tests.

The impacted rock fragments were collected after SHPB tests, and the physical photos of the fractured samples are shown in Figure 13.

As shown in Figure 13, the crushing degrees are serious with the strain rate increase. The crushing degrees of granite-rubber composite specimens are much smaller than for the granite-granite composite specimens, and the results express the better energy-absorbing characteristic of highdamping rubber directly. To make a quantitative description, the mass distribution of rock fragments was filtered by different-purpose sifters. The filtered results are shown in Table 2.

Using the data in Table 1, the slopes of the double logarithmic and fractal dimension of different composite specimens were fitted and are shown in Figures 14(a) and 14(b), respectively.

As indicated in Figure 14, the fractal dimension of composite specimens increases with the impact energy improvement. The higher fractal dimension expressed that the rock sample was cracked more seriously, and the crushing particle size is smaller. There is an obvious energy-absorbed effect of high-damping rubber by contrasting the fractal dimensions between the granite-granite composite specimens and granite-rubber composite specimens, as in Figure 14(b).

4.4. Optimal Thickness-Diameter Ratio for Energy Absorbing. In Figure 7 , there is not any transmitted energy under impact with different strain rates, and, in Figure 8, there is a linear relationship between absorbed energy and incident energy. The above analysis results mean that there is a potential thickness-diameter ratio of high-damping rubber. To obtain the optimal thickness-diameter ratio, six groups of thickness-diameter ratios $(6 / 10,5 / 10,4 / 10,3 / 10,2 / 10$, and $1 / 10$ ) of rubber samples were tested by the SHPB system with different strain rates. After calculating the test data, the curves between incident energy and absorbed energy under different thickness-diameter ratios were fitted, as shown in Figure 15.

As shown in Figure 15, with the increase in the incident energy, the energy-absorbed rates are still in linear form at $6 / 10,5 / 10$, and $4 / 10$ thickness-diameter ratios; for the $3 / 10$ thickness-diameter ratio, the energy-absorbed rate becomes nonlinear in form, and the energy-absorbed rate begins to 
TABLE 2: Filtered results of mass distribution of fragment size.

\begin{tabular}{lcccccccccccc}
\hline \multirow{2}{*}{ Serial no. } & \multicolumn{1}{c}{} & \multicolumn{1}{c}{ Accumulated mass under sifter/kg } & \multicolumn{4}{c}{ Fractal dimension } \\
& 0.15 & 0.3 & 0.6 & 1.18 & 2.36 & 4.75 & 9.5 & 13.2 & 16 & 19 & 26.65 & \\
\hline GG1 $\left(200 \mathrm{~s}^{-1}\right)$ & 12.7 & 18 & 26.9 & 39.8 & 51.4 & 68 & 93 & 122.6 & 147.2 & 159.8 & 164 & 2.50 \\
GG2 $\left(300 \mathrm{~s}^{-1}\right)$ & 16.9 & 26.9 & 35.2 & 45.1 & 64.2 & 78.5 & 115.7 & 131 & 143.4 & 156.3 & 162.7 & 2.57 \\
GG3 $\left(400 \mathrm{~s}^{-1}\right)$ & 31.4 & 42.9 & 53.2 & 62.5 & 78.3 & 89.5 & 111.2 & 129.4 & 145.1 & 159.5 & 163.2 & 2.69 \\
GR1 $\left(200 \mathrm{~s}^{-1}\right)$ & 0.8 & 1.7 & 3 & 4.5 & 9.5 & 15.2 & 23.3 & 35.3 & 45.3 & 57.2 & 81.9 & 2.15 \\
GR2 $\left(300 \mathrm{~s}^{-1}\right)$ & 1.1 & 2 & 4 & 7.3 & 14.4 & 24.3 & 36.4 & 40.7 & 52.8 & 81 & 82.6 & 2.17 \\
GR3 $\left(400 \mathrm{~s}^{-1}\right)$ & 2.7 & 3.5 & 6.5 & 11.9 & 21.2 & 35 & 58.3 & 70.2 & 78.1 & 80.7 & 81.8 & 2.28 \\
\hline
\end{tabular}
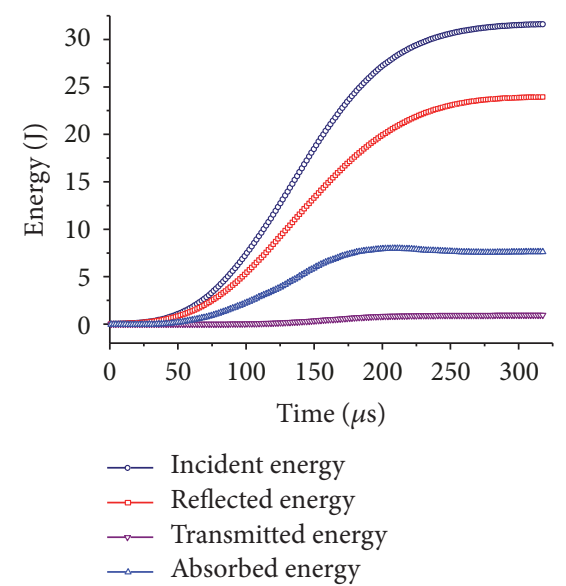

(a) Granite-granite $200 \mathrm{~s}^{-1}$

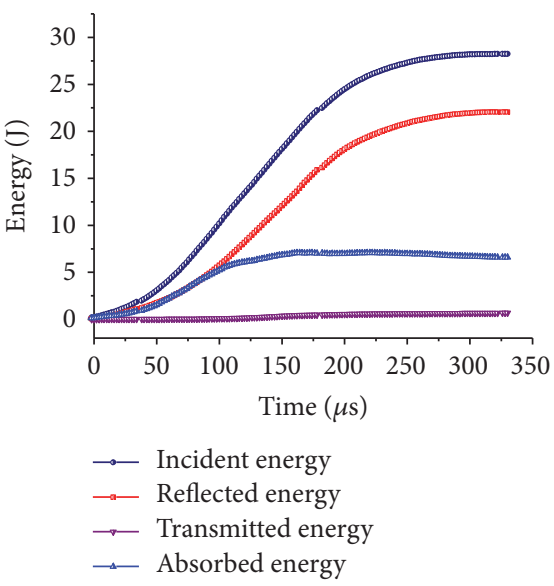

(d) Granite-rubber $200 \mathrm{~s}^{-1}$
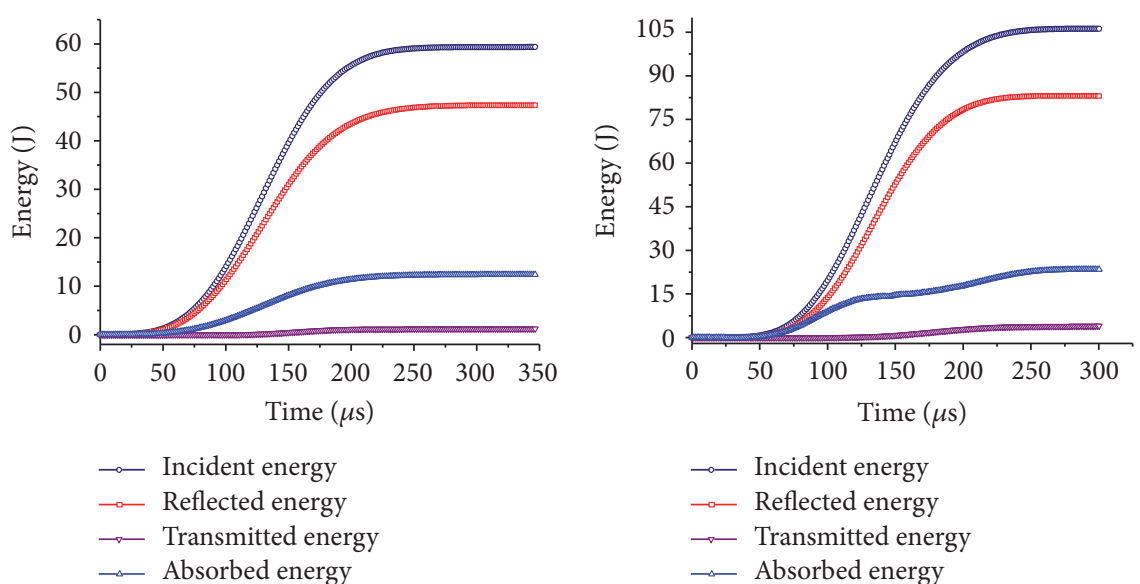

(b) Granite-granite $300 \mathrm{~s}^{-1}$

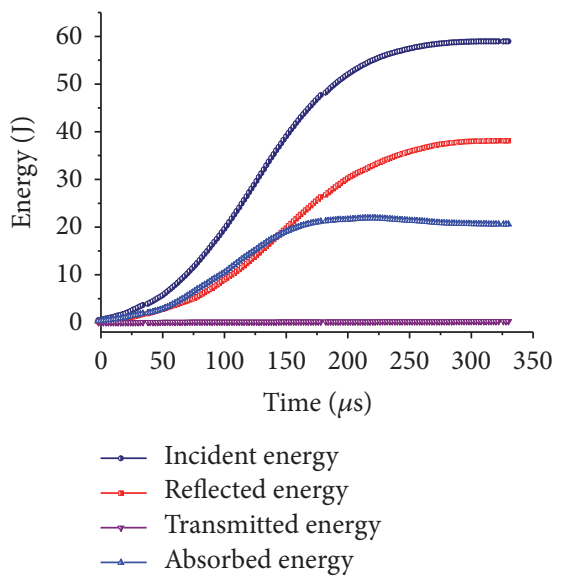

(e) Granite-rubber $300 \mathrm{~s}^{-1}$ $\multimap$ Incident energy

$\because$ Reflected energy

$\rightarrow$ Transmitted energy

$\multimap$ Absorbed energy

(c) Granite-granite $400 \mathrm{~s}^{-1}$

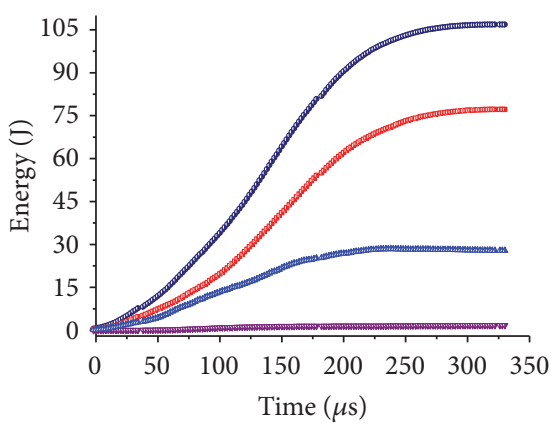

$\rightarrow$ Incident energy

$\longrightarrow$ Reflected energy

-_ Transmitted energy

$\rightarrow$ Absorbed energy

(f) Granite-rubber $400 \mathrm{~s}^{-1}$

FIGURE 12: Energy distribution results of composite specimens in SHPB tests.

decrease as the incident energy increases. Thus, the optimal thickness-diameter ratio for energy absorbing is from $3 / 10$ to $4 / 10$ under the condition of less than $1 \times 10^{7} \mathrm{~J} / \mathrm{m}^{3}$ incident energy density.

\section{Discussion}

Taking as an example one of the main roadways in the Sanshandao gold mine, the roadway is excavated along the maximum horizontal principal stress, and the value of the vertical principal stress is close to the minimum horizontal principal stress (at a depth of $1000 \mathrm{~m}$, the vertical principal stress is $27 \mathrm{MPa}$, and the minimum horizontal principal stress is $25.4 \mathrm{MPa}$ ); the excavated roadway can be equivalent to an infinite-roundness roadway with a $4.2-\mathrm{m}$ radius. In addition, the far-field geostress effect can be approximate to hydrostatic pressure, which means $P_{0}=\sigma_{v} \approx \sigma_{h}$. Using the plane strain problem method and rock mechanics theory, it is easy to calculate that the maximum accumulated energy of the roadway is $116.65 \mathrm{~kJ} / \mathrm{m}^{3}$. According to the value of the elastic 


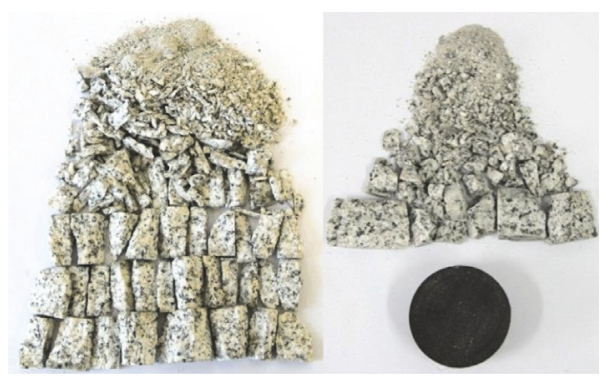

(a) $200 \mathrm{~s}^{-1}$

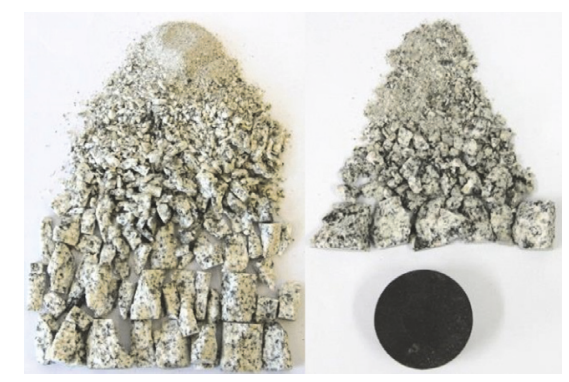

(b) $300 \mathrm{~s}^{-1}$

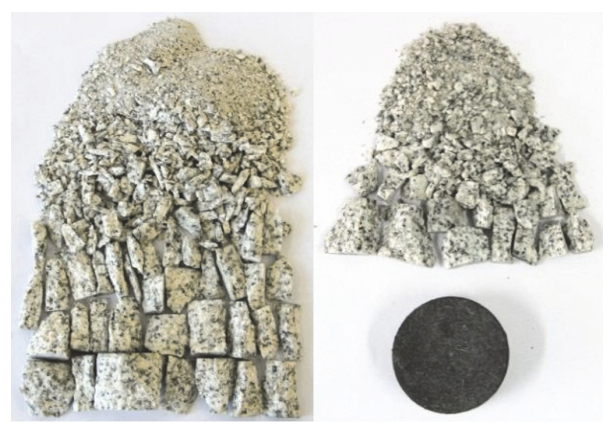

(c) $400 \mathrm{~s}^{-1}$

FIGURE 13: Physical photos of cracked samples under strain rates.

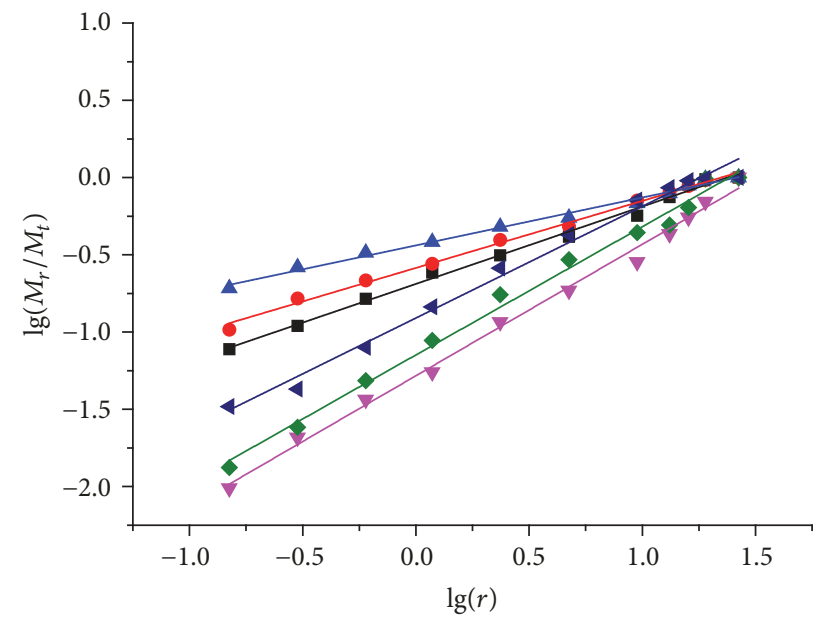

- G-G1 $\left(200 \mathrm{~s}^{-1}\right)$ — Slope: 0.5009

- G-G2 $\left(300 \mathrm{~s}^{-1}\right)$ — Slope: 0.4338

\ G-G3 $\left(400 \mathrm{~s}^{-1}\right)$ — Slope: 0.3097

$\nabla$ G-R1 $\left(200 \mathrm{~s}^{-1}\right)$ - Slope: 0.8508

- G-R2 $\left(300 \mathrm{~s}^{-1}\right)$ — Slope: 0.8294

G-R3 $\left(400 \mathrm{~s}^{-1}\right)$ - Slope: 0.7227

(a)

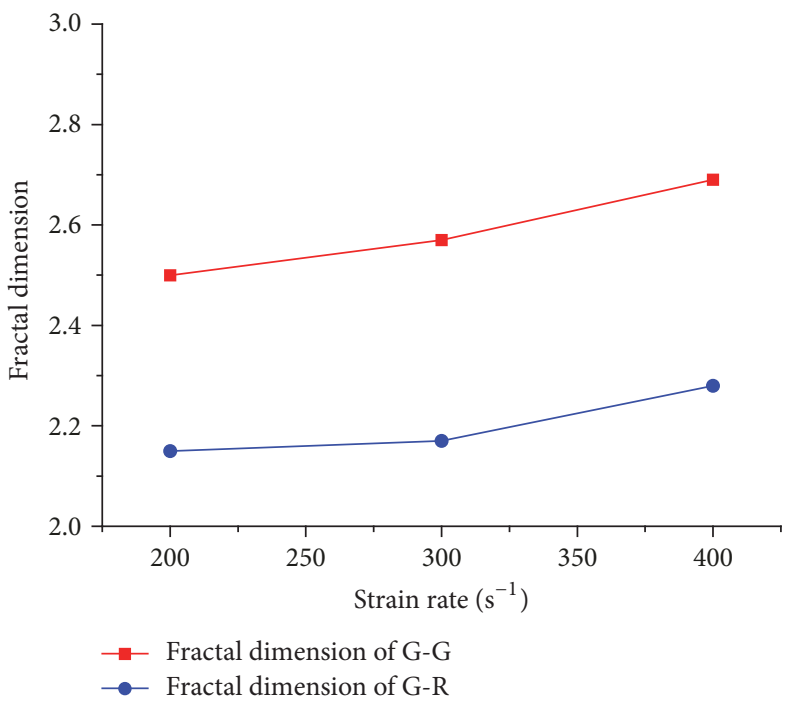

(b)

FIGURE 14: Slope of double logarithmic and fractal dimension of different composite specimens.

energy criterion, the rockburst intensity can be divided into four degrees, as shown in Table 3.

As calculated above, without considering the R-bolt support method, the maximum accumulated energy of the roadway is $116.65 \mathrm{~kJ} / \mathrm{m}^{3}$ after excavation. This value indicates that the rockburst intensity is "medium." After considering an approximately $25 \%$ energy-absorbing rate, the absorbed value is $29.16 \mathrm{~kJ} / \mathrm{m}^{3}$. Then, the accumulated energy is reduced to $87.49 \mathrm{~kJ} / \mathrm{m}^{3}$ of the roadway, so the rockburst intensity becomes "slight." The R-bolt obviously decreases the probability and intensity of the rockburst, which reduces the potential threat of a rockburst to a certain extent. 
TABLE 3: Grading value of rockburst tendentiousness [37].

\begin{tabular}{lcccc}
\hline Rockburst degree & None & Slight & Medium & Intensity \\
\hline Energy density value $(\mathrm{kJ} / \mathrm{m} 3)$ & $U_{e}<40$ & $40 \leq U_{e}<100$ & $100 \leq U_{e}<200$ & $200<U_{e}$ \\
\hline
\end{tabular}

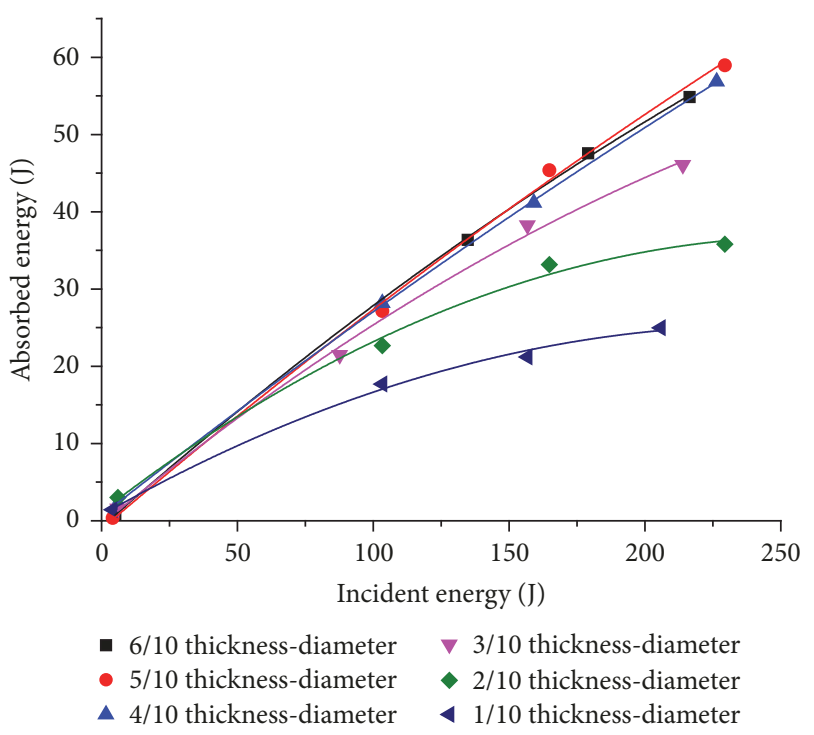

FIGURE 15: Curves between absorbed energy and incident energy under different thickness-diameter ratios.

With rapid development of energy-absorbing materials, many new products are proposed. A representative material is aluminum honeycomb. Many scholars have done research on its material properties. Ivañez et al. (2017) studied the compressive deformation and energy absorption capability of aluminum honeycomb cores [39]. Al Antali et al. (2017) researched the energy-absorbing properties of composite tube-reinforced aluminum honeycomb [40]. Furthermore, enormous advantages, such as light weight and a wide range of strain rates, were found in the above studies. Because of the limitations of the energy-absorbing characteristic of plastic deformation, however, the aluminum honeycomb cannot repeatedly be used. This is why the selected energyabsorbing material is high-damping rubber in this work. In addition, the difference between the R-bolt and the above lager deformation bolts is that the R-bolt can consume the stored energy repeatedly.

Based on the above systematic tests and simple calculations, the presented energy-absorbing bolt (R-bolt) was found to have a good energy-absorbing characteristic under high-strain-rate impacts. Comparison with existing bolts and typical energy-absorbing material shows that the R-bolt can prevent rockburst in hard rock and consume the stored energy repeatedly.

\section{Conclusions}

To reduce the probability and strength of rockbursts in deep hard rock, considering the limitations of current energyabsorbing bolts and taking advantage of high-damping rubber, a novel energy-absorbing bolt, the R-bolt, was designed by employing high-damping rubber. Then, a series of SHPB tests of high-damping rubber were done. Some important results were obtained.

(1) The absorbed energy is linear to the total incident energy, which means the high-damping rubber can consume more energy under stronger impact. Under an impact load of $600 \mathrm{~s}^{-1}$, the input energy is $205.8 \mathrm{~J}$, absorbed energy is $60.89 \mathrm{~J}$, and energy-absorbing rate is $29.6 \%$.

(2) The energy-absorbing rates under different environmental temperatures $\left(22^{\circ} \mathrm{C}, 30^{\circ} \mathrm{C}, 40^{\circ} \mathrm{C}, 50^{\circ} \mathrm{C}\right.$, and $60^{\circ} \mathrm{C}$ ) are $29.6 \%, 28.4 \%, 27.5 \%, 23.9 \%$, and $21.4 \%$, respectively. The testing results show that the energy-absorbing rate decreases with the increase in environmental temperature. There is an obvious inflection point at $40^{\circ} \mathrm{C}$. This means that the environmental temperatures will produce a negative effect on the energy-absorbing rate, especially for more than $40^{\circ} \mathrm{C}$ temperatures.

(3) The fractal dimensions of composite specimens increase with increase in the impact energy. The higher fractal dimension expressed that the rock sample was cracked more seriously, and the crushing particle size is smaller. The testing result shows that there is an obvious energyabsorbing effect of high-damping rubber by contrasting the fractal dimensions between the granite-granite composite specimens and granite-rubber composite specimens.

(4) With the increase in the incident energy, the energyabsorbing rates are still linear at 5/10 and 4/10 thicknessdiameter ratios, and, for the $3 / 10$ thickness-diameter ratio, the energy-absorbing rate becomes nonlinear, and the energy-absorbing rate begins to decrease along with the incident energy increase. Thus, the optimal thickness-diameter ratio of energy absorbing is from $3 / 10$ to $4 / 10$ under the condition of less than the $1 \times 10^{7} \mathrm{~J} / \mathrm{m}^{3}$ incident energy density.

Last, based on the above systematic tests, the presented energy-absorbing bolt (R-bolt) was proved to have a good energy-absorbing characteristic under a high-strain-rate impact. In comparison with other bolts and typical energyabsorbing materials, the R-bolt can prevent rockbursts in hard rock and can consume the stored energy repeatedly.

\section{Conflicts of Interest}

The authors declare that they have no conflicts of interest.

\section{Acknowledgments}

This work has been supported by the State Key Research Development Program of China (no. 2016YFC0600703) and the National Natural Science Foundation of China (nos. 51704014 and 51674013). 


\section{References}

[1] W. Guo, Y. Li, D. Yin, S. Zhang, and X. Sun, "Mechanisms of rock burst in hard and thick upper strata and rock-burst controlling technology," Arabian Journal of Geosciences, vol. 9, no. 10, pp. 561-571, 2016.

[2] T. Li, C. Ma, M. Zhu, L. Meng, and G. Chen, "Geomechanical types and mechanical analyses of rockbursts," Engineering Geology, vol. 222, pp. 72-83, 2017.

[3] G. Chen, T. Li, G. Zhang, H. Yin, and H. Zhang, "Temperature effect of rock burst for hard rock in deep-buried tunnel," Natural Hazards, vol. 72, no. 2, pp. 915-926, 2014.

[4] G.-L. Feng, X.-T. Feng, B.-R. Chen, and Y.-X. Xiao, "Microseismic sequences associated with rockbursts in the tunnels of the Jinping II hydropower station," International Journal of Rock Mechanics and Mining Sciences, vol. 80, pp. 89-100, 2015.

[5] X.-T. Feng, Y. Yu, G.-L. Feng, Y.-X. Xiao, B.-R. Chen, and Q. Jiang, "Fractal behaviour of the microseismic energy associated with immediate rockbursts in deep, hard rock tunnels," Tunnelling and Underground Space Technology, vol. 51, pp. 98-107, 2016.

[6] Q. Jiang, X.-T. Feng, T.-B. Xiang, and G.-S. Su, "Rockburst characteristics and numerical simulation based on a new energy index: a case study of a tunnel at 2,500 m depth," Bulletin of Engineering Geology and the Environment, vol. 69, no. 3, pp. 381388,2010 .

[7] J. Kornowski and J. Kurzeja, "Prediction of rockburst probability given seismic energy and factors defined by the expert method of hazard evaluation (MRG)," Acta Geophysica, vol. 60, no. 2, pp. 472-486, 2012.

[8] B. Sirait, R. K. Wattimena, and N. P. Widodo, "Rockburst prediction of a cut and fill mine by using energy balance and induced stress," Procedia Earth and Planetary Science, vol. 6, pp. 426-434, 2013.

[9] L. Weng, L. Huang, A. Taheri, and X. Li, "Rockburst characteristics and numerical simulation based on a strain energy density index: a case study of a roadway in Linglong gold mine, China," Tunnelling and Underground Space Technology, vol. 69, pp. 223232, 2017.

[10] H. He, L. Dou, J. Fan, T. Du, and X. Sun, "Deep-hole directional fracturing of thick hard roof for rockburst prevention," Tunnelling and Underground Space Technology, vol. 32, pp. 34-43, 2012.

[11] P. Konicek, K. Soucek, L. Stas, and R. Singh, "Long-hole destress blasting for rockburst control during deep underground coal mining," International Journal of Rock Mechanics and Mining Sciences, vol. 91, pp. 141-153, 2013.

[12] Q. Zhu, Y. Feng, M. Cai, J. Liu, and H. Wang, "Interpretation of the extent of hydraulic fracturing for rockburst prevention using microseismic monitoring data," Journal of Natural Gas Science and Engineering, vol. 38, pp. 107-119, 2017.

[13] Ł. Wojtecki and P. Konicek, "Estimation of active rockburst prevention effectiveness during longwall mining under disadvantageous geological and mining conditions," Journal of Sustainable Mining, vol. 15, no. 1, pp. 1-7, 2016.

[14] F. Meng, H. Zhou, Z. Wang et al., "Experimental study on the prediction of rockburst hazards induced by dynamic structural plane shearing in deeply buried hard rock tunnels," International Journal of Rock Mechanics and Mining Sciences, vol. 86, pp. 210-223, 2016.

[15] M. Ghadimi, K. Shahriar, and H. Jalalifar, "An Analytical Model to Predict Shear Stress Distribution in Fully Encapsulated Rock
Bolts," Geotechnical and Geological Engineering, vol. 33, no. 1, pp. 59-68, 2015.

[16] L. P. Srivastava and M. Singh, "Empirical estimation of strength of jointed rocks traversed by rock bolts based on experimental observation," Engineering Geology, vol. 197, pp. 103-111, 2015.

[17] T. Nguyen, K. Ghabraie, and T. Tran-Cong, "Simultaneous pattern and size optimisation of rock bolts for underground excavations," Computers \& Geosciences, vol. 66, pp. 264-277, 2015.

[18] K. Zhang, G. Zhang, R. Hou, Y. Wu, and H. Zhou, "Stress evolution in roadway rock bolts during mining in a fully mechanized longwall face, and an evaluation of rock bolt support design," Rock Mechanics and Rock Engineering, vol. 48, no. 1, pp. 333-344, 2015.

[19] B. Zhang, S. Li, K. Xia et al., "Reinforcement of rock mass with cross-flaws using rock bolt," Tunnelling and Underground Space Technology, vol. 51, pp. 346-353, 2016.

[20] M. Mohammadi, M. F. Hossaini, and H. Bagloo, "Rock bolt supporting factor: rock bolting capability of rock mass," Bulletin of Engineering Geology and the Environment, vol. 76, no. 1, pp. 231-239, 2017.

[21] W. D. Ortlepp, "The design of support for the containment of rockburst damage in tunnelsan engineering approach," in Rock Support in Mining and Underground Construction, P. K. Kaiser and D. R. McCreath, Eds., pp. 593-609, Rotterdam, Netherlands, Balkema, 1992.

[22] A. Ansell, "Laboratory testing of a new type of energy absorbing rock bolt," Tunnelling and Underground Space Technology, vol. 20, no. 4, pp. 291-300, 2005.

[23] A. Ansell, "Dynamic testing of steel for a new type of energy absorbing rock bolt," Journal of Constructional Steel Research, vol. 62, no. 5, pp. 501-512, 2006.

[24] C. C. Li, "A new energy-absorbing bolt for rock support in high stress rock masses," International Journal of Rock Mechanics and Mining Sciences, vol. 47, no. 3, pp. 396-404, 2010.

[25] C. C. Li, "Performance of D-bolts under static loading," Rock Mechanics and Rock Engineering, vol. 45, no. 2, pp. 183-192, 2012.

[26] C. C. Li and C. Doucet, "Performance of D-bolts under dynamic loading," Rock Mechanics and Rock Engineering, vol. 45, no. 2, pp. 193-204, 2012.

[27] G. Wang, X. Wu, Y. Jiang, N. Huang, and S. Wang, "Quasistatic laboratory testing of a new rock bolt for energy-absorbing applications," Tunnelling and Underground Space Technology, vol. 38, pp. 122-128, 2013.

[28] M. C. He, W. L. Gong, J. Wang et al., "Development of a novel energy-absorbing bolt with extraordinarily large elongation and constant resistance," International Journal of Rock Mechanics \& Mining Sciences, vol. 67, pp. 29-42, 2014.

[29] Y. Liang, M. He, C. Cao, S. Wang, and T. Ren, "A mechanical model for conebolts," Computers \& Geosciences, vol. 83, pp. 142151, 2017.

[30] A. Reggio and M. De Angelis, "Combined primary-secondary system approach to the design of an equipment isolation system with High-Damping Rubber Bearings," Journal of Sound and Vibration, vol. 333, no. 9, pp. 2386-2403, 2014.

[31] F. Hedayati Dezfuli and M. S. Alam, "Performance-based assessment and design of FRP-based high damping rubber bearing incorporated with shape memory alloy wires," Engineering Structures, vol. 61, pp. 166-183, 2014.

[32] D. A. Nguyen, J. Dang, Y. Okui, A. F. M. S. Amin, S. Okada, and T. Imai, "An improved rheology model for the description 
of the rate-dependent cyclic behavior of high damping rubber bearings," Soil Dynamics and Earthquake Engineering, vol. 77, pp. 416-431, 2015.

[33] Q. T. Nguyen, V. Tinard, and C. Fond, "The modelling of nonlinear rheological behaviour and Mullins effect in High Damping Rubber," International Journal of Solids and Structures, vol. 75-76, pp. 235-246, 2015.

[34] A. A. Markou and G. D. Manolis, "Mechanical models for shear behavior in high damping rubber bearings," Soil Dynamics and Earthquake Engineering, vol. 90, pp. 221-226, 2016.

[35] C. Alhan, H. Gazi, and H. Kurtuluş, "Significance of stiffening of high damping rubber bearings on the response of base-isolated buildings under near-fault earthquakes," Mechanical Systems and Signal Processing, vol. 79, pp. 297-313, 2016.

[36] V. H. Cu, B. Han, and D. H. Pham, “Tuned mass-high damping rubber damper on a taut cable," KSCE Journal of Civil Engineering, vol. 21, no. 3, pp. 928-936, 2017.

[37] Q. F. Guo and Q. W. Li, "Based on the linear elastic energy criterion to analyze rock burst tendency in deep rock mass," Energy Education Science and Technology Part A: Energy Science and Research, vol. 32, no. 6, pp. 2307-2312, 2014.

[38] L. Cheng, Y. Zhang, M. Ji, K. Zhang, and M. Zhang, "Experimental studies on the effects of bolt parameters on the bearing characteristics of reinforced rock," SpringerPlus, vol. 5, no. 1, article 866, 2016.

[39] I. Ivañez, L. M. Fernandez-Cañadas, and S. Sanchez-Saez, "Compressive deformation and energy-absorption capability of aluminium honeycomb core," Composite Structures, vol. 174, pp. 123-133, 2017.

[40] A. Al Antali, R. Umer, J. Zhou, and W. J. Cantwell, “The energyabsorbing properties of composite tube-reinforced aluminum honeycomb," Composite Structures, vol. 176, pp. 630-639, 2017. 


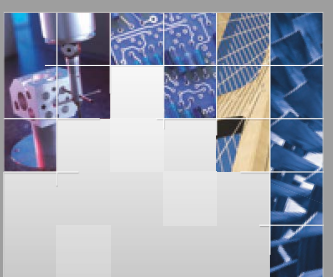

\section{Enfincering}
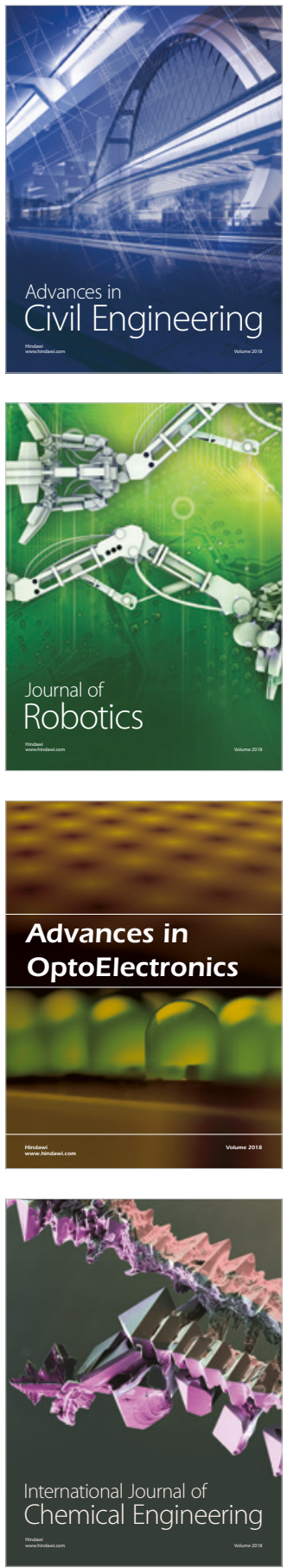

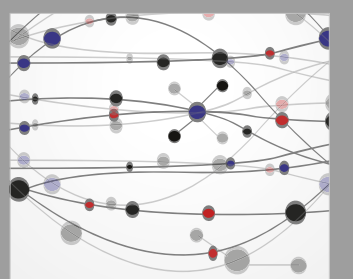

\section{Rotating \\ Machinery}

The Scientific World Journal

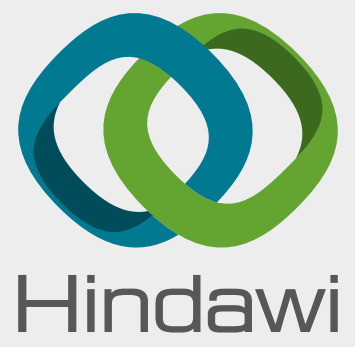

Submit your manuscripts at

www.hindawi.com
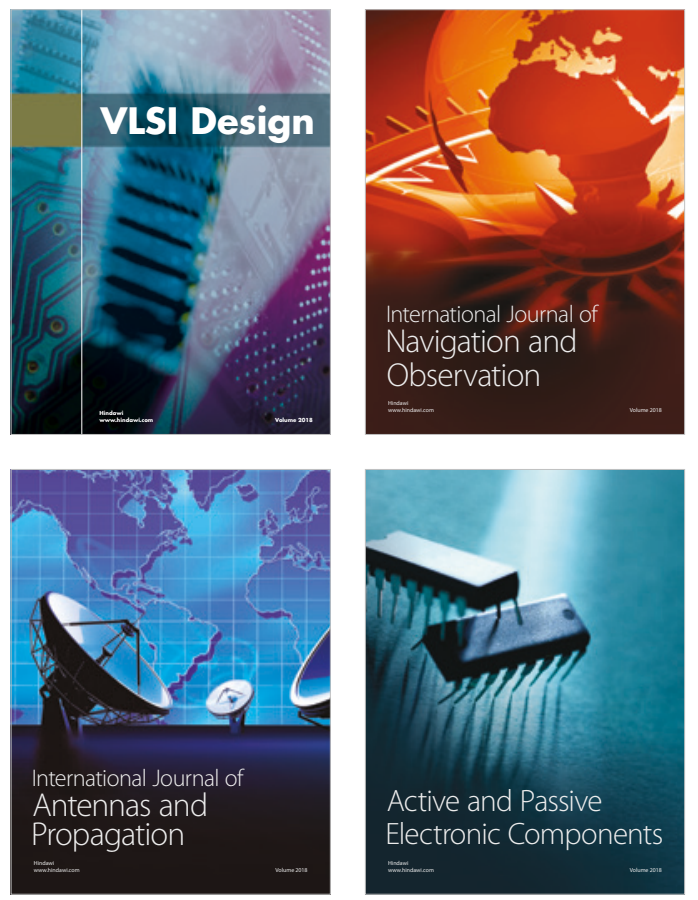
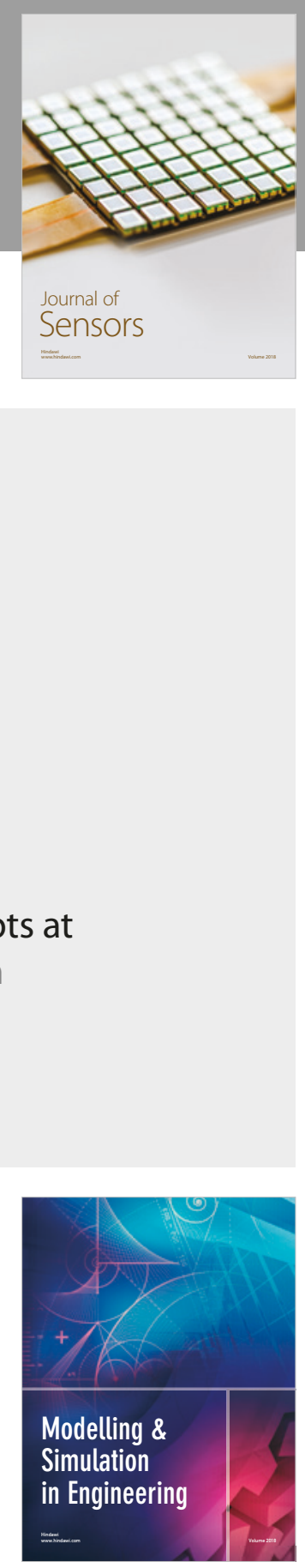

\section{Advances \\ Multimedia}
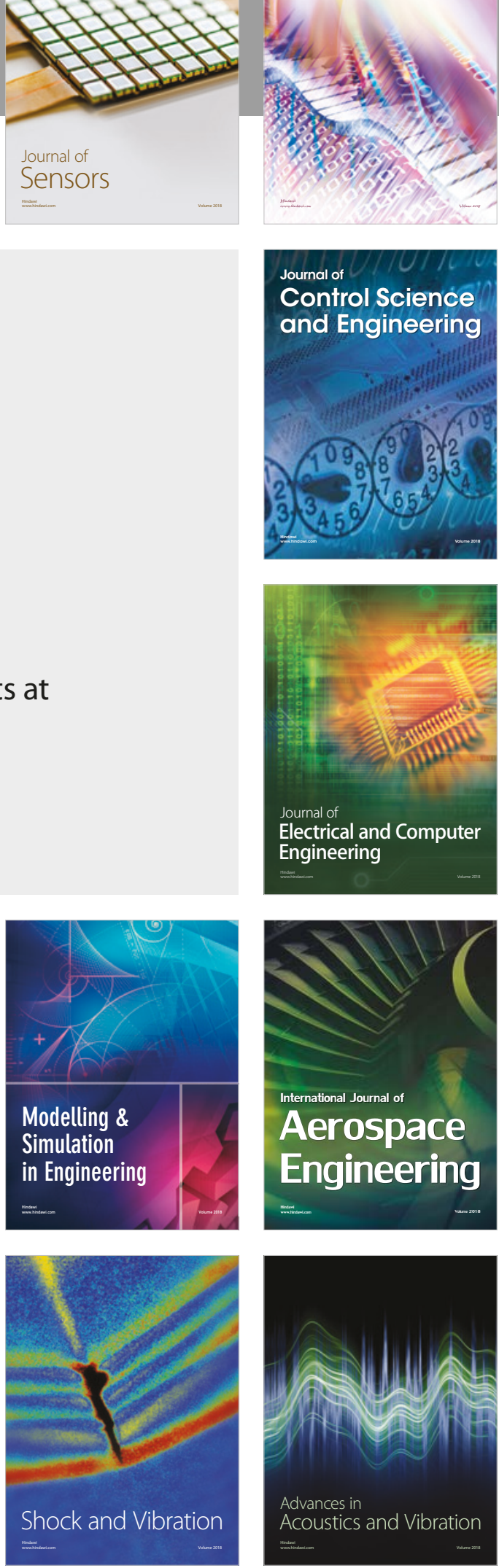